\title{
BMJ Global Health Excess deaths reveal unequal impact of COVID-19 in Ecuador
}

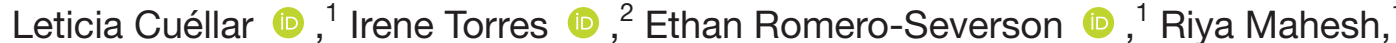 \\ Nathaniel Ortega, ${ }^{1}$ Sarah Pungitore (1) , ${ }^{1}$ Ruian Ke (ㄷ , ${ }^{1}$ Nicolas Hengartner (i) ${ }^{1}$
}

To cite: Cuéllar L, Torres I, Romero-Severson E, et al. Excess deaths reveal unequal impact of COVID-19 in Ecuador. BMJ Global Health 2021;6:e006446. doi:10.1136/ bmjgh-2021-006446

Handling editor Seye Abimbola

Received 28 May 2021 Accepted 9 September 202

Check for updates

\section{(c) Author(s) (or their} employer(s)) 2021. Re-use permitted under CC BY-NC. No commercial re-use. See rights and permissions. Published by BMJ

${ }^{1}$ Los Alamos National Laboratory, Los Alamos, New Mexico, USA

${ }^{2}$ Fundacion Octaedro, Quito, Ecuador

Correspondence to

Dr Leticia Cuéllar;

leticia@lanl.gov

\section{ABSTRACT}

Latin America has struggled to control the transmission of COVID-19. Comparison of excess death (ED) rates during the pandemic reveals that Ecuador is among the highest impacted countries. In this analysis, we update our previous findings with the most complete all-cause mortality records available for 2020 , disaggregated by sex, age, ethnicity and geography. Our study shows that in 2020 , Ecuador had a $64 \%$ ED rate $(95 \% \mathrm{Cl} 63 \%$ to $65 \%)$ or $64 \%$ more deaths than expected. Men had a higher ED rate, $75 \%$ (95\% $\mathrm{Cl} 73 \%$ to $76 \%$ ), than women's $51 \%$ (95\% Cl $49 \%$ to $52 \%$ ), and this pattern of higher EDs for men than women held for most age groups. The only exception was the 20-29 age group, where women had $19 \%$ more deaths, compared to $10 \%$ more deaths for men, but that difference is not statistically significant. The analysis provides striking evidence of the lack of COVID-19 diagnostic testing in Ecuador: the confirmed COVID-19 deaths in 2020 accounted for only $21 \%$ of total EDs. Our significant finding is that indigenous populations, who typically account for about $5 \%$ of the deaths, show almost four times the ED rate of the majority mestizo group. Indigenous women in each age group have higher ED rates than the general population and, in ages between 20 and 49 years, they have higher ED rates than indigenous men. Indigenous women in the age group 20-29 years had an ED rate of $141 \%$, which is commensurate to the ED rate of indigenous women older than 40 years.

\section{INTRODUCTION}

The impact of COVID-19 in Latin America has reached the levels of a humanitarian crisis, amplifying the effects of structural socioeconomic inequalities in the region. ${ }^{1}$ Governments struggled to mitigate and suppress disease transmission in the general population. However, less resources were allocated to indigenous populations, ${ }^{2}$ which was revealed by their application for judicial protection. In Ecuador, the combination of limited testing and lack of monitoring of symptomatic cases limits knowledge of the trajectory of the COVID-19 pandemic and on co-circulating variants of interest. Comparison of excess death (ED) rates during the pandemic confirms that Ecuador is among the top $20 \%$ impacted countries in the world.
Summary box

The impact of COVID-19 in Latin America became a humanitarian crisis in 2020, amplifying the effects of structural socioeconomic inequalities.

- Ecuador had $64 \%(95 \% \mathrm{Cl} 63 \%$ to $65 \%)$ more deaths than expected, one of the highest excess death (ED) rates in the world, with only $20 \%$ of those being officially attributable to COVID-19 due to limited SARSCoV-2 testing. The indigenous population had 125\% more deaths than expected, and in the general population, men had higher or equal EDs than women in all age categories.

- The patterns of EDs as a function of age and sex are different for the indigenous population: indigenous people aged from 60 to 69 years had $200 \%(95 \%$ Cl $183 \%$ to $216 \%$ ) more deaths than expected, and indigenous women aged from 20 to 29 years had an ED rate four times higher than that of same-aged men.

- Increased disease surveillance programmes targeting the most affected subpopulations, including postmortem confirmatory testing of suspected cases, can improve situational awareness of public health to better allocate needed resources.

In our previous study, ${ }^{4}$ we found that during the pandemic (from January to September 2020) all-cause mortality increased by $71 \%$ ( $70 \%$ to $72 \%$ ) from that observed in years prior to the COVID-19 outbreak. Our analysis further revealed a disproportionately large ED rate among the Ecuadorian indigenous populations.

In this note, we update our previous findings with the most complete Ecuadorian death records available for 2020, disaggregated by sex, age and ethnicity, to improve our quantification of the impact of COVID-19. The aim of this paper is to present a systematic description of the magnitude of COVID-19 related deaths by sex, ethnicity and age in Ecuador. Root cause analysis for observed deviations from typical COVID-19 death profiles observed throughout the world-increased deaths with age and higher death rates for men-requires more than a statistical analysis 
linking social and ethnographic factors to EDs, which is beyond the scope of this paper.

\section{ESTIMATING MORTALITY RATES}

Most countries have used the official number of daily incidence and deaths attributable to SARS-CoV-2 to measure the impact of the COVID-19 pandemic. These quantities depend on testing capacity, which can lead to a biased image of the spread of COVID-19 if testing levels are low or unequally distributed across the population. A more reliable measure, as attested by the US National Academies of Sciences, Engineering, and Medicine ${ }^{5}$ are EDs, defined as the difference between the number of all-cause deaths during the pandemic and the number of expected deaths in the absence of the COVID-19 for 2020. The expected number of deaths in the absence of COVID-19 was modelled using the reported mortality data in previous years. Specifically, we use mortality data from 2015 to 2019 to estimate the baseline death counts to be compared with the recorded deaths from 1 January 2020 to 29 December 2020. The uncertainty in the expected baseline of deaths is captured by $95 \%$ CIs obtained by fitting our model to resampled mortality data from 2015 to 2019. These intervals are used to compute all the CIs presented as ranges of discussed quantities in the text and table 1 .

In countries with reliable death reporting systems, EDs are a more reliable measure of the true impact of COVID-19. It aggregates deaths directly attributable to SARS-CoV-2 infections with fatalities indirectly associated with the COVID-19 pandemic, such as deaths due to lack of adequate medical treatment that occurs when the healthcare systems are overburdened. When interpreted as a measure of deaths associated with COVID-19, ED may, in certain subpopulations, have a negative bias because generally protective behavioural changes might also prevent deaths for causes other than COVID-19. EDs are not necessary a reliable image of the dynamics of COVID-19, due to intrinsic variability in case fatality rates over time and space (ie, more or fewer persons might die given a constant incidence depending on who was being infected). However, EDs are a powerful measure of the burden of a new disease for which official records may not be reliable.

To compare EDs across different groups, we use two measurements: (1) the ED Factor, which is the ratio of number of all-cause deaths during the pandemic to the number of expected deaths in the absence of COVID-19 and (2) the ED rate, which is the change in mortality during the pandemic relative to the expected mortality, calculated as the number of EDs over the expected deaths. Neither of these two measures depend on the size of the (sub)populations being compared. To illustrate, an ED factor of 1.5 is equivalent to a $50 \%$ ED rate, corresponding to $50 \%$ more deaths than expected.

The reporting of deaths is often delayed, which can limit the ability of ED analysis to address real-time needs.
However, Ecuador has a relative short death reporting delay compared with other countries, partly due to the fact that the deceased cannot be buried without an official death certificate. In a typical year, death records collected up to the middle of February would have contained $98.8 \%$ of all the deaths that occurred in the previous year. However, as could be expected, the burden of the pandemic resulted in longer reporting delays in Ecuador.

As a result, the updated 2020 death counts are mostly only slightly $(1 \%-2 \%)$ larger than the death counts used in the original study. Only during the peak of the pandemic are the revised death counts 3\%-4\% larger than originally reported. Death reports may also miss useful information. While under normal circumstances, all but $5 \%$ report ethnicity of the decease, during 2020 , the rate of missing ethnicity rose to $24 \%$. Finally, due to limited diagnostic and postmortem testing for SARS-CoV-2, only $21 \%$ of the EDs in 2020 are officially attributed to COVID-19.

Our previous analysis of ED from January to September 2020 , showed that there were $71 \%$ (70\% to $72 \%)$ more deaths than expected in Ecuador, that men had a higher ED rate, $83 \%$ ( $81 \%$ to $85 \%$ ), than women, who had $56 \%$ ( $54 \%$ to $58 \%$ ), and that EDs increased with age, although the ED mortality rate was highest for people aged from 60 to 69 years $(133 \% ; 129 \%$ to $137 \%)$. This new study covers all of 2020 and reveals that the ED rate decreased to $64 \%$ (63\% to $65 \%$ ) (ie, there were between $63 \%$ and $65 \%$ more deaths than expected), lowering the overall ED rate for men to $75 \%$ ( $73 \%$ to $76 \%)$ and for women to $51 \%(49 \%$ to $52 \%)$. This means that towards the end of 2020, the overall impact of COVID-19 on mortality rates had decreased.

This trend of lower ED rates by the end of 2020 also applies to all age groups for people over 50 and for those under 10 years of age. However, the ED rates increased for all people aged 10-50 (see table 1 and online supplemental figure S3). Specifically, EDs by age group still show that the most affected group is the 60-69 years old with $112 \%$ (108\% to $115 \%$ ) more deaths than expected, followed by age groups 70-79 and 50-59 years old, with $96 \%$ (93\% to $98 \%$ ) and $88 \%$ (83\% to $91 \%$ ) more deaths than expected, respectively. By contrast, the age groups $40-49$ and 80 years and older in the original study had nearly the same ED rate, $63 \%(58 \%$ to $68 \%)$ and $62 \%$ (60\% to $64 \%$ ), but when accounting for all deaths until the end of the year, the 80 years and older age group finished the year with $54 \%$ (52\% to 56\%) more deaths than expected compared with $69 \%$ (64\% to $73 \%$ ) for the 40-49 age group.

The age group 30-39 years also ended the year with a higher per cent of EDs, $34 \%$ (25\% to $41 \%$ ) than the one measured back in September, 2020, which was $24 \%$ (15\% to $33 \%$ ). Finally, the age groups $20-29$ and $10-19$ years old showed an increased ED rate in the new study, but since those groups had lower than expected deaths back in September, they were minimally affected by 


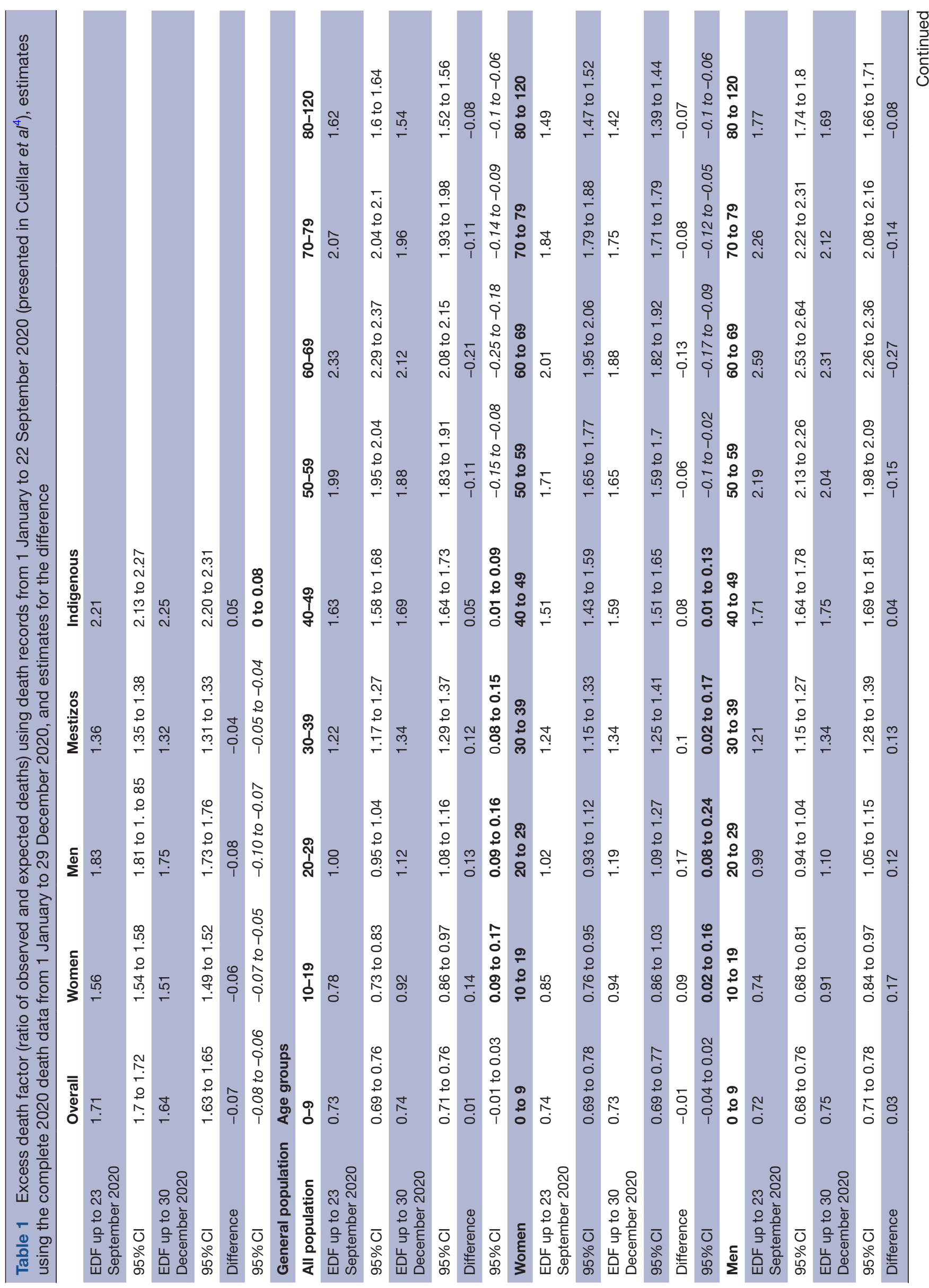




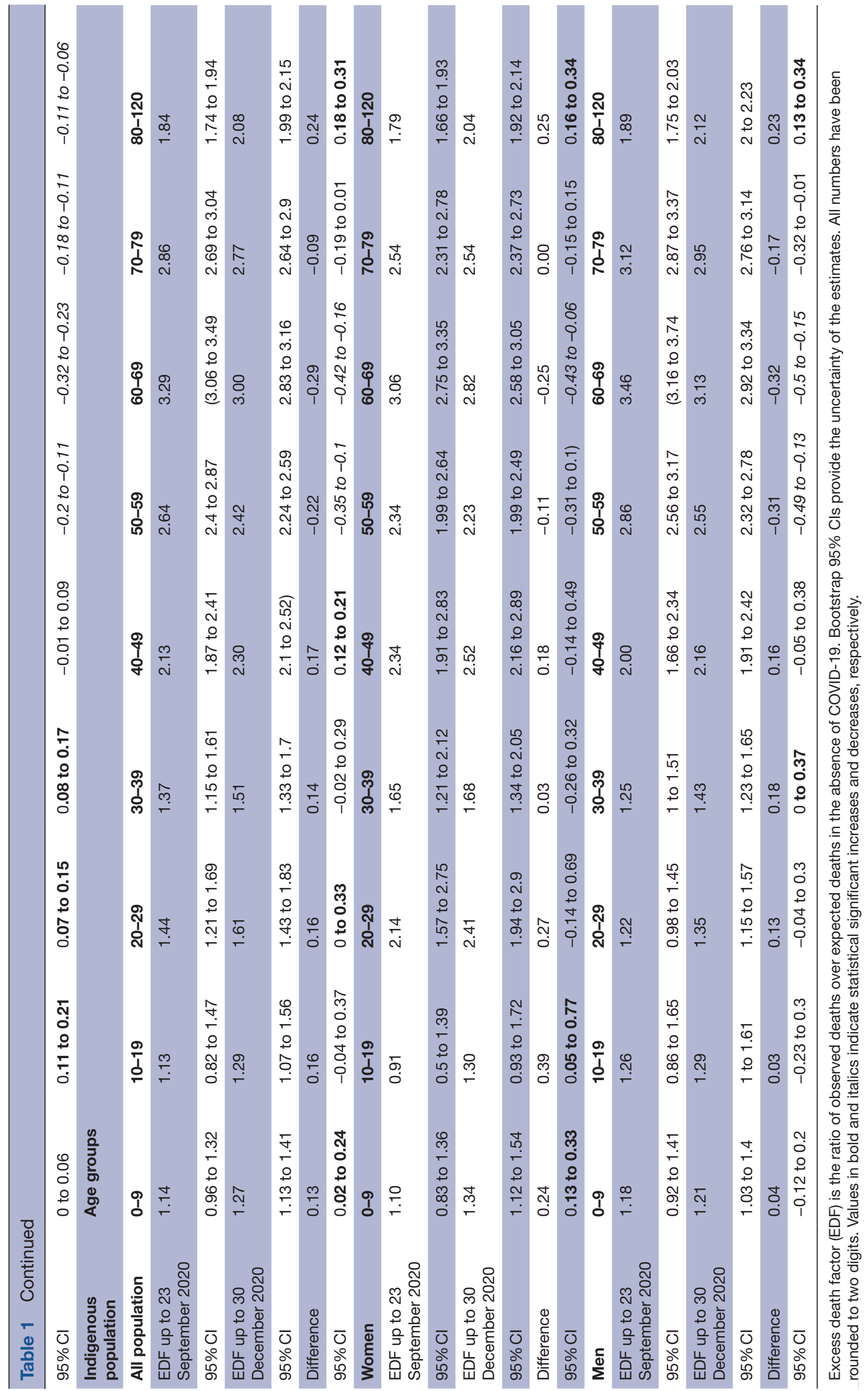



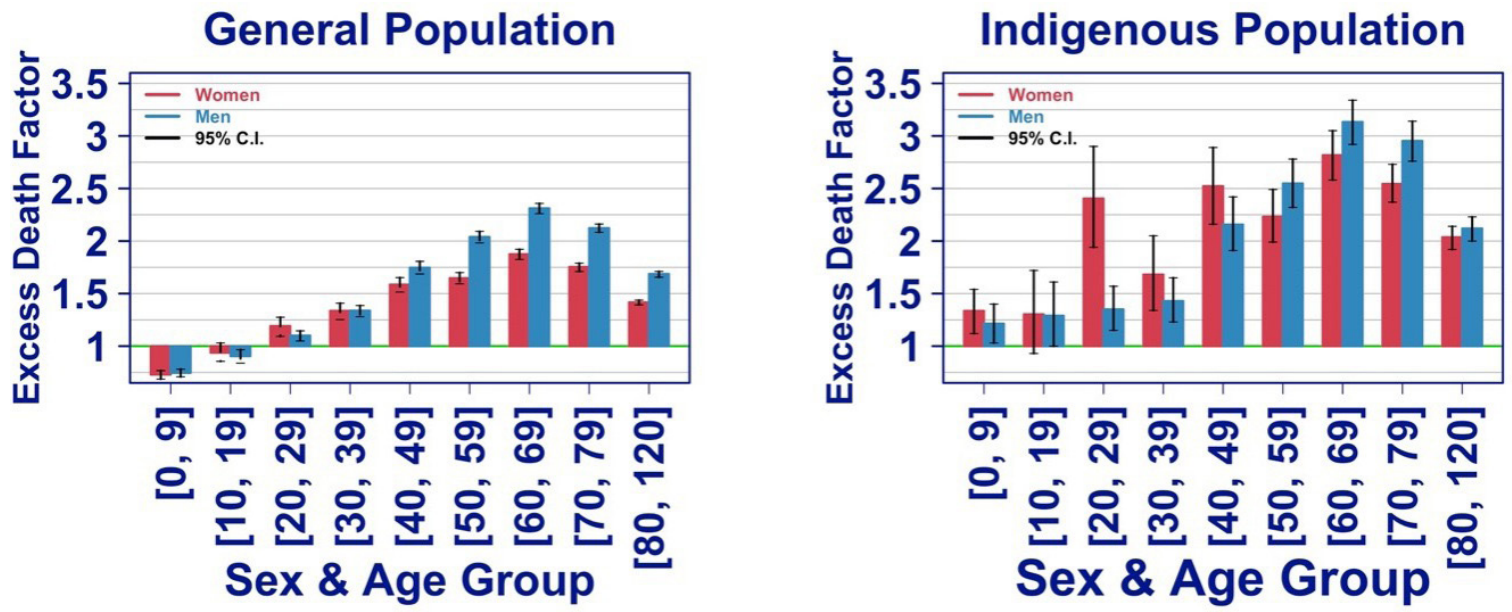

Figure 1 Excess death factor by sex and age group for the general and the indigenous populations.

the pandemic. At the end, there were less deaths than expected for people younger than 20 years.

Patterns are consistent for EDs by age group for women and men across the entire population as indicated in the left panel of figure 1, that also shows higher ED rates for men than women across age groups, except for the age group 20-29 years where women show $19 \%$ (9\% to $27 \%$ ) more EDs than expected compared with $10 \%$ (5\% to $15 \%$ ) for men.

Geographically, most provinces ended the year with similar ED rates than those measured at the end of September. Statistically significant changes include, Guayas and Santa Elena, the two provinces most impacted early in the pandemic, with 20 (95\% CI $-22 \%$ to $-18 \%)$ and $22(95 \% \mathrm{CI}-31 \%$ to $-14 \%)$ percentage points lower in $\mathrm{ED}$ rate than as measured at the end of September; other significant decreases in ED rates are El Oro $(-7 \%$; $95 \%$ CI $3 \%$ to $12 \%)$ and Los Rios $(-4 \%$; $95 \%$ CI $-8 \%$ to $-1 \%)$. Only Azuay had a 7\% (95\% CI 3\% to 10\%) statistically significant increase in ED rate. Online supplemental figure S1 shows the final ED factor for all 24 provinces. The strict national lockdown put in place in mid-March of 2020, 2-3 weeks prior to these provinces' EDs peaks in late March and early April, most likely prevented further deaths and particularly, such high levels of EDs as the ones observed in Guayas and Santa Elena at the beginning of the pandemic.

Limitations in diagnostic testing in Ecuador are striking. ${ }^{6}$ In Chile, a country of similar characteristics, EDs have matched attributable COVID-19 deaths. ${ }^{7}$ In Ecuador, confirmed COVID-19 deaths in 2020 accounted for only 21\% of total EDs (compared with 20\% until 22 September 2020), showing no significant improvement in testing.

\section{HIGHER IMPACT IN INDIGENOUS GROUPS}

Of the two major ethnic groups in Ecuador for which ethnicity is recorded in the death registry, the mestizo group that typically accounts for about $84 \%$ of the registered deaths ended 2020 with 32\% (31\% to 33\%) more deaths than expected. In contrast, the indigenous group that typically accounts for about $5 \%$ of the deaths, shows almost four times the ED rate than the mestizo group, with $125 \%$ ( $120 \%$ to $131 \%$ ) more deaths than expected. Online supplemental figure S2 shows the 2020 time series of the weekly ED factor by sex and ethnic groups.

\section{UNUSUAL DEATH PATTERNS IN WOMEN}

Comparison of the left and right panels in figure 1 shows that the indigenous group had a higher ED rate across all sex and age groups than the general population. Notably, indigenous women not only have higher EDs rate for each age group than in the general population, but had higher ED rate for ages between 20 and 50 years than indigenous men. Among indigenous women, the age group 20-29 years was the fourth worse group impacted with an excess rate of $141 \%$ (94\% to $190 \%$ ).

\section{CONCLUSION}

Our follow-up study has demonstrated the high and otherwise hidden burden of COVID-19 in Ecuador through 2020. We found a shift in mortality to younger age groups and a continuing, disproportional burden of EDs in indigenous populations. For the general population, men remain more impacted than women for all age groups. That pattern changes for the indigenous population, where in some age groups, women have a statistically significant higher EDs. In particular, indigenous women in the age group 20-29 have four times higher ED rate than their men counterpart. Our study does not reveal the cause of this large disparity.

Given that the indigenous population has been historically underserved, there is the potential to remedy the observed unequal disease burden by alleviating barriers of access to health services, related to testing, management of COVID-19 and detection and treatment of other conditions.

The country's centralised epidemiological surveillance has continued to rely on PCR confirmation while 
suffering from severe limitations in laboratory capacity. Learning from other countries, Ecuador could benefit from systematically monitoring both symptomatic and confirmed cases like in Chile, and to use testing massively to promptly detect outbreaks. Similarly, to maximise limited resources, postmortem testing ${ }^{8}$ could help to improve knowledge on transmission, especially of variants that may be more lethal.

Twitter Irene Torres @lairene1

Contributors Conceptualisation: LC and IT; data acquisition: IT; data processing: LC, RM, NO, SP, ER-S; methodology and formal analysis: LC and NH; visualisation and writing: IT, LC, NH, ER-S and RK.

Competing interests None declared.

Patient consent for publication Not applicable.

Provenance and peer review Not commissioned; externally peer reviewed.

Data availability statement Data may be obtained from a third party and are not publicly available.

Supplemental material This content has been supplied by the author(s). It has not been vetted by BMJ Publishing Group Limited (BMJ) and may not have been peer-reviewed. Any opinions or recommendations discussed are solely those of the author(s) and are not endorsed by BMJ. BMJ disclaims all liability and responsibility arising from any reliance placed on the content. Where the content includes any translated material, BMJ does not warrant the accuracy and reliability of the translations (including but not limited to local regulations, clinical guidelines, terminology, drug names and drug dosages), and is not responsible for any error and/or omissions arising from translation and adaptation or otherwise.

Open access This is an open access article distributed in accordance with the Creative Commons Attribution Non Commercial (CC BY-NC 4.0) license, which permits others to distribute, remix, adapt, build upon this work non-commercially, and license their derivative works on different terms, provided the original work is properly cited, appropriate credit is given, any changes made indicated, and the use is non-commercial. See: http://creativecommons.org/licenses/by-nc/4.0/.

\section{ORCID iDs}

Leticia Cuéllar http://orcid.org/0000-0002-4159-3223

Irene Torres http://orcid.org/0000-0002-0516-3090

Ethan Romero-Severson http://orcid.org/0000-0002-8082-1225

Sarah Pungitore http://orcid.org/0000-0001-5782-6741

Ruian Ke http://orcid.org/0000-0001-5307-8934

Nicolas Hengartner http://orcid.org/0000-0002-4157-134X

\section{REFERENCES}

1 The Lancet. COVID-19 in Latin America: a humanitarian crisis. Lancet 2020;396:1463.

2 ECLAC. The impact of COVID-19 on Indigenous peoples in Latin America (Abya Yala): between invisibility and collective resistance. Commission for Latin America and the Caribbean (ECLAC), 2021.

3 The Economist. Tracking COVID-19 excess deaths across countries, 2021. Available: https://www.economist.com/graphic-detail/ coronavirus-excess-deaths-tracker

4 Cuéllar L, Torres I, Romero-Severson E. Excess deaths reveal the true spatial, temporal, and demographic impact of COVID-19 on mortality in Ecuador. International Journal of Epidemiology. In Press 2021;2021.

5 National Academies of Sciences, Engineering, and Medicine. Evaluating data types: a guide for decision makers using data to understand the extent and spread of COVID-19. Washington, DC: The National Academies Press, 2020

6 Torres I, Sippy R, Sacoto F. Assessing critical gaps in COVID-19 testing capacity: the case of delayed results in Ecuador. BMC Public Health 2021;21:637.

7 Mena GE, Martinez PP, Mahmud AS, et al. Socioeconomic status determines COVID-19 incidence and related mortality in Santiago, Chile. Science 2021;372:eabg5298.

8 Mwananyanda L, Gill CJ, MacLeod W, et al. COVID-19 deaths in Africa: prospective systematic postmortem surveillance study. BMJ 2021;372:n334. 